\title{
Composição Corporal de Bovinos de Quatro Raças Zebuínas, Abatidos em Diferentes Estádios de Maturidade ${ }^{1}$
}

\author{
André Mendes Jorge ${ }^{2}$, Carlos Augusto de Alencar Fontes ${ }^{3}$, Mário Fonseca Paulino 4
}

\begin{abstract}
RESUMO - Este trabalho foi realizado com o objetivo de avaliar a composição química corporal de 63 animais não-castrados das raças Gir, Guzerá, Mocho de Tabapuã e Nelore, em confinamento, com pesos vivos médios iniciais de 376,4; 357,6, 362,0; e 368,6 kg, respectivamente. Em cada raça, os animais foram divididos em cinco categorias: abate inicial, alimentação ad libitum com ração contendo $50 \%$ de concentrado até atingirem pesos individuais de abate de 405,450 e $500 \mathrm{~kg}$, respectivamente, e, finalmente, categoria alimentação restrita recebendo a mesma ração, suprindo níveis de proteína e energia 15\% acima da mantença. Não houve diferenças entre as raças quanto aos conteúdos corporais de proteína, gordura, energia e macroelementos minerais ( $\mathrm{Ca}, \mathrm{P}, \mathrm{Mg}, \mathrm{Ke} \mathrm{Na}$ ). Os animais abatidos com pesos mais elevados apresentam menores porcentagens de proteína e macroelementos minerais ( $\mathrm{Ca}, \mathrm{P}, \mathrm{Mg}, \mathrm{K}$ e $\mathrm{Na}$ ) no corpo, ocorrendo o inverso para a gordura corporal.
\end{abstract}

Palavras-chave: bovinos de corte, composição corporal, exigências nutricionais, Gir, Guzerá, Mocho Tabapuã, Nelore

\section{Body Composition of Four Zebu Breed Beef Cattle Slaughtered at Different Stages of Maturity}

\begin{abstract}
This work was conducted to evaluate the chemical body composition of sixty three young bulls, from the Gyr, Guzera, Mocho Tabapuã, Nellore breeds, in feedlot, averaging, respectively, 376.4, 357.6, 362.0, and 368.6 kg of initial live weight. The animals from each breed were divided into five categories: initial slaughter, full fed diet containing $50 \%$ concentrate until the individual slaughter weights of 405, 450 and $500 \mathrm{~kg}$, respectively, and finally the category restricted feeding fed the same diet supplying levels of protein and energy $15 \%$ above maintenance. There were no differences among breed regarding to body content of protein, fat, energy and macrominerals $(\mathrm{Ca}, \mathrm{P}, \mathrm{Mg}, \mathrm{K}$ and $\mathrm{Na}$ ). The animals slaughtered at higher weights showed lower percentage of body protein and macrominerals $(\mathrm{Ca}, \mathrm{P}, \mathrm{Mg}, \mathrm{K}$ and $\mathrm{Na})$, and occurring the inverse to the body fat.
\end{abstract}

Key Words: beef cattle, body composition, nutritional requirements, Gyr, Guzera, Mocho Tabapuã, Nellore

\section{Introdução}

No Brasil, nos últimos anos, esforços têm sido desenvolvidos no sentido de se estudarem a composição corporal e as exigências nutricionais de zebuínos e mestiços, destacando-se os trabalhos de GONÇALVES (1988), CARVALHO (1989), LANA et al. (1992a, b, c, d), PIRES et al. (1993a, b, c, d), SOARES (1994), FREITAS (1995), ESTRADA (1997) e PAULINO (1996). Entretanto, as informações disponíveis são ainda limitadas, em virtude de sua determinação ser trabalhosa e de alto custo.

Torna-se necessário ampliar o banco de informações sobre as raças zebuínas, a fim de estabelecer planos de nutrição compatíveis com o potencial genético dos animais, bem como criar pontos de abate que proporcionem eficiência de ganho e características desejáveis de carcaça.
O objetivo deste estudo foi avaliar, em confinamento, a composição química corporal de bovinos das raças Gir, Guzerá, Nelore e Mocho Tabapuã, abatidos em diferentes estádios de maturidade.

\section{Material e Métodos}

Este estudo foi realizado no Laboratório de Animais do Departamento de Zootecnia da Universidade Federal de Viçosa.

Utilizaram-se 63 bovinos machos não-castrados, sendo 16 Gir (GIR), 16 Guzerá (GUZ), 15 Nelore (NEL) e 16 Mocho Tabapuã (TAB), com idade média de 24 meses e pesos médios iniciais de $357,6 \pm 32,95$; $362,0 \pm 28,95 ; 376,4 \pm 28,56$; e $368,6 \pm 25,83 \mathrm{~kg}$, respectivamente, provenientes da Empresa de Pesquisa Agropecuária de Minas Gerais (EPAMIG).

\footnotetext{
1 Parte da Tese apresentada à UFV pelo primeiro autor, para obtenção do título de Doctor Scientiae. Trabalho realizado em colaboração com a EPAMIG/FAPEMIG.

2 Professor Assistente Doutor do DPEA/ UNESP - Faz. Lageado, Caixa Postal 560 - 18618-000 - Botucatu - SP.

3 Professor Titular UENF - 28015-620 - Campos - RJ.

${ }^{4}$ Professor do Departamento de Zootecnia da UFV, Viçosa-MG
} 
Os animais foram mantidos em regime de confinamento, distribuídos aleatoriamente em baias individuais, com área total concretada de $30 \mathrm{~m}^{2}$, sendo $8 \mathrm{~m}^{2}$ cobertos com telhas de amianto, providas de comedouro e bebedouro de concreto.

Os animais de cada raça foram distribuídos em cinco grupos, cada um designado, aleatoriamente, para um dos tratamentos:

$\mathrm{AB}$ - Abate inicial ou referência;

AR - Alimentação restrita;

1 - Alimentação ad libitum até o abate, a peso vivo de $405 \mathrm{~kg}$, equivalente a $90 \%$ do peso estimado à maturidade das vacas da raça;

2 - Alimentação ad libitum até o abate, a peso vivo de $450 \mathrm{~kg}$, equivalente a $100 \%$ do peso estimado à maturidade das vacas da raça; e

3 - Alimentação ad libitum até o abate, a peso vivo de $500 \mathrm{~kg}$, equivalente a $110 \%$ do peso estimado à maturidade das vacas da raça.

No tratamento $\mathrm{AB}$ foram alocados quatro animais das raças Gir, Guzerá e Mocho-Tabapuã e três da raça Nelore. Nos demais tratamentos foram alocados três animais de cada raça.

O período de adaptação teve duração de 60 dias, fornecendo-se a todos os animais a dieta utilizada no período experimental, ad libitum. Após o período de adaptação, foram abatidos os animais do grupo AB, servindo como referência no estudo da composição corporal inicial dos animais.

Os animais dos tratamentos 1, 2 e 3 receberam, durante o período experimental, dieta balanceada $\mathrm{ad}$ libitum, formulada segundo as normas do NRC (1984), de modo a permitir ganho diário de $1,1 \mathrm{~kg}$, atendendo, ao mesmo tempo, às exigências de proteína degradável no rúmen (PDR) e proteína não-degradável no rúmen (PNDR), segundo o ARC (1980). Procurou-se sempre manter a proporção concentrado: volumoso próxima de 1:1, na matéria seca (MS). A dieta foi fornecida aos animais da categoria AR em quantidades limitadas, de forma a ingerirem quantidades de energia e proteína $15 \%$ acima das exigências de mantença.

A composição percentual da dieta experimental é apresentada na Tabela 1 e os teores de matéria seca (MS), proteína bruta (PB), energia metabolizável (EM) e macroelementos minerais dos ingredientes e da dieta encontram-se na Tabela 2.

O período experimental não teve duração préfixada, uma vez que os animais foram abatidos assim que atingiram os pesos preestabelecidos de 405, 450 ou $500 \mathrm{~kg}$, correspondentes aos tratamentos 1, 2 e 3 , respectivamente.
Para cada raça, na medida em que um animal da categoria 2 atingia o peso de abate, o animal do grupo AR mais semelhante quanto ao peso e à condição corporal, no início do experimento, era também abatido.

Antes do período de adaptação, os animais foram pesados, após jejum de 16 horas, identificados com brincos numerados, submetidos ao controle de endo e ectoparasitas e receberam 2.000.000 UI de vitamina A injetável.

Os animais foram pesados a cada 28 dias e, à medida que cada um se aproximava do peso de abate preestabelecido, era pesado a intervalos menores, de forma a ser abatido com o peso previsto.

Antes do abate, os animais foram submetidos a período de jejum de 16 horas, com livre acesso à água. $\mathrm{O}$ abate ocorreu após pesagem do animal, por concussão cerebral e posterior seção da veia jugular. De cada animal abatido, pesaram-se e coletaram-se amostras de sangue, rúmen-retículo, omaso, abomaso, intestino delgado, intestino grosso, mesentério, carne industrial, gordura interna, fígado, coração, rins, baço, pulmão, língua, couro, cauda, esôfago, traquéia e aparelho reprodutor. Para um animal de cada raça, foram pesadas, dissecadas e retiradas amostras de uma cabeça e um pé.

A carcaça foi dividida em duas metades, pesadas individualmente e resfriadas em câmara fria, por aproximadamente 18 horas, à temperatura de $-5^{\circ} \mathrm{C}$. Decorrido este tempo, utilizou-se a metade esquerda da carcaça, retirou-se a seção transversal, incluindo a $9^{\mathrm{a}}, 10^{\mathrm{a}}$ e $11^{\mathrm{a}}$ costelas, da qual se destacou a seção HH, segundo HANKINS e HOWE (1946).

Tabela 1 - Composição percentual da dieta experimental (\% MS)

Table 1 - Percentage composition of the experimental diet (\%DM) Ingrediente $\%$

Ingredient

Feno de capim-braquiária $\quad 50,34$

Brachiaria grass hay

Milho grão triturado $\quad 38,00$

Ground corn grain

Farelo de soja $\quad 10,00$

Soybean meal

Uréia

0,77

Urea

Mistura mineral $^{1} \quad 0,89$

Mineral premix

${ }^{1}$ Fosfato bicálcico (dicalcium phosphate), 79,16\%; calcário (limestone), $7,9 \%$; cloreto de sódio (sodium chloride), $9,63 \%$; sulfato de zinco (zinc sulfate), $1,0 \%$; sulfato de cobre (copper sulfate), $0,25 \%$; cloreto de potássio (potassium chloride), $0,03 \%$; sulfato de cobalto(cobalt sulfate), $0,03 \%$. 
Tabela 2 - Composição química do feno, do concentrado e da dieta experimental (\%MS) Table 2 - Chemical composition of hay, concentrate and of the experimental diet (\%DM)

\begin{tabular}{|c|c|c|c|c|c|c|c|c|}
\hline \multirow[t]{2}{*}{ Item } & \multicolumn{8}{|c|}{$\begin{array}{l}\text { Teor na matéria seca } \\
\text { Dry matter content }\end{array}$} \\
\hline & $\begin{array}{c}\mathrm{MS}^{1}(D M) \\
(\%)\end{array}$ & $\begin{array}{c}\mathrm{EM}^{2}(M E) \\
\mathrm{Mcal} / \mathrm{kg}\end{array}$ & $\mathrm{PB}(C P)$ & $\mathrm{Ca}$ & $\mathrm{P}$ & $\mathrm{Mg}$ & $\mathrm{Na}$ & $\mathrm{K}$ \\
\hline $\begin{array}{l}\text { Feno } \\
\text { Hay }\end{array}$ & 83,48 & - & 4,44 & 0,34 & 0,08 & 0,13 & 0,03 & 0,96 \\
\hline $\begin{array}{l}\text { Concentrado } \\
\text { Concentrate }\end{array}$ & 84,10 & - & 21,10 & 0,50 & 0,36 & 0,06 & 0,10 & 0,66 \\
\hline $\begin{array}{l}\text { Dieta } \\
\text { Diet }\end{array}$ & 83,78 & 2,42 & 12,71 & 0,42 & 0,22 & 0,09 & 0,06 & 0,81 \\
\hline
\end{tabular}

As amostras de sangue, carne, gordura, couro, osso, cauda e amostras compostas de vísceras e órgãos foram processadas conforme descrito por PAULINO (1996), que determinou as exigências nutricionais dos animais utilizados neste trabalho.

As análises de nitrogênio total foram feitas em aparelho semimicro Kjeldahl; as de extrato etéreo, em aparelho Goldfish; e as de cinza, em mufla elétrica a $600{ }^{\circ} \mathrm{C}$. Na determinação dos macroelementos minerais, foi preparada solução mineral pela via úmida. $\mathrm{O}$ fósforo foi determinado em espectrofotômetro (colorímetro), segundo o método adaptado por BRAGA e DEFILIPO (1979). O cálcio e o magnésio foram determinados em espectrofotômetro de absorção atômica (aparelho Varian, modelo AA-175) e o sódio e o potássio, em espectrofotômetro de chama (Corning, modelo 400). As análises foram realizadas conforme metodologia descrita por SILVA (1990).

A composição química corporal foi determinada considerando-se o peso e a composição de cada parte do corpo (sangue, couro, cauda, vísceras e órgãos) e dos componentes isolados (músculos, tecido adiposo e osso) da seção $\mathrm{HH}$, da cabeça e dos pés.

Os conteúdos corporais de proteína, gordura, energia e cinzas foram obtidos conforme descrito por PAULINO (1996).

O peso corporal vazio dos animais referência (AB) foi determinado somando-se o peso de carcaça, sangue, cabeça, pés, couro, cauda, vísceras e órgãos. Relações específicas entre o peso corporal vazio (PCVZ) e o peso vivo (PV) foram determinadas para animais de cada raça. $\mathrm{O}$ valor obtido para cada raça foi utilizado para se estimar o PCVZ inicial dos animais experimentais das categorias remanescentes (AR, 1, 2 e 3). O PCVZ final destes animais foi determinado de modo semelhante ao obtido pelos animais-referência, por ocasião do abate.

A relação observada para os animais $\mathrm{AB}$, entre o peso de carcaça e o peso corporal vazio, foi utilizada para estimar o peso inicial de carcaça dos animais remanescentes.

As análises estatísticas foram feitas utilizando-se o programa LSMLMW, versão PC-1, segundo HARVEY (1987).

Para análise utilizou-se o modelo abaixo:

em que

$$
Y_{i j k}=\mu+R_{i}+C_{j}+R C_{i j}+E_{i j k}
$$

$\mathrm{Y}_{\mathrm{ijk}}=$ observação referente ao animal k, da raça i e categoria $\mathrm{j}$;

$\mu=$ média geral;

$\mathrm{R}_{\mathrm{i}}=$ efeito da raça $\mathrm{i}$, em que $\mathrm{i}=1$, (GIR); 2, (GUZ); 3,(NEL); 4, (TAB);

$\mathrm{C}_{\mathrm{j}}=$ efeito da categoria $\mathrm{j}$, em que $\mathrm{j}=1,(\mathrm{AB}) ; 2$, (AR); 3, (1); 4, (2); 5, (3);

$\mathrm{RC}_{\mathrm{ij}}=$ efeito da interação entre raça i e categoria j; e

$\mathrm{e}_{\mathrm{ijk}}=$ erro aleatório, pressuposto normalmente distribuído, com média zero e variância $\sigma^{2}$.

O efeito de regressão, por raça e geral, do PCVZ inicial para as características estudadas foi pesquisado em análises preliminares, sendo excluído do modelo, por não se mostrar significativo.

As médias foram comparadas pelo teste Tukey a $5 \%$ de probabilidade.

\section{Resultados e Discussão}

As análises de variância para conteúdos corporais totais de proteína, gordura, energia e macroelementos minerais mostraram não haver efeito significativo de interação entre raças (GIR, GUZ, NEL e TAB) e categorias (AB, AR, 1, 2 e 3), sendo, portanto, os dois efeitos considerados independentes. 
$\mathrm{Na}$ Tabela 3 são apresentados os valores médios dos conteúdos corporais totais de proteína, gordura e energia e na Tabela 4, os valores médios dos conteúdos corporais totais de macroelementos minerais, dos animais para as quatro raças, obtidos conforme descrito por PAULINO (1996).

Não se observou diferença entre raças quanto ao parâmetros supracitados. Os valores médios dos conteúdos corporais totais de proteína e gordura (\%PCVZ) e energia (Mcal/kg PCVZ), foram 2,3; 12,4 ; e $7,22 \%$ superiores, respectivamente, aos valores médios estimados por PAULINO (1996), utilizando-se equações de regressão, para os mesmos animais do presente estudo, com pesos de 300 a 500 $\mathrm{kg}$, nas quais não foram incluídos os animais submetidos à restrição alimentar. Estes resultados são bastante próximos aos valores médios estimados encontrados por FREITAS (1995) e ESTRADA (1997), para animais Nelore, utilizando-se metodologia semelhante à empregada neste trabalho. FONTES (1995), analisando os dados de vários experimentos em conjunto e tomando como referência o Nelore não-castrado, na faixa de 200 a $400 \mathrm{~kg}$ PCVZ, encontrou valores estimados para a proteína, gordura e energia, $10,73 \%$ superior, $26,9 \%$ e $3,67 \%$ inferiores, respectivamente, aos do presente estudo.

Os valores médios de conteúdos corporais totais (em \% PCVZ) de cálcio, fósforo e potássio foram 2,26; 2,40; e 4,76\% inferiores e os de magnésio e sódio, iguais, respectivamente, aos valores médios estimados por PAULINO (1996), que não incluiu, ao ajustar as equações, os animais submetidos à alimentação restrita.

$\mathrm{Na}$ Tabela 5 são apresentados os conteúdos corporais totais de proteína, gordura e energia e na Tabela 6, os conteúdos corporais totais de macroelementos minerais, dos animais para os cinco tratamentos (AB, AR, 1, 2 e 3), obtidos conforme descrito por PAULINO (1996).

Observou-se que animais mais pesados (tratamento 3) apresentaram maiores $(\mathrm{P}<0,05)$ conteúdos totais de proteína, gordura e energia que animais mais leves (tratamentos AB, AR, 1 e 2). Todavia, em termos de concentrações, ou seja, em \% do PCVZ ou $\mathrm{Mcal} / \mathrm{kg}$ de PCVZ, com a elevação do peso de abate, houve decréscimo no conteúdo corporal de proteína e aumento na concentração de gordura, com incremento concomitante no conteúdo de energia. Estes resultados, semelhantes aos relatados por PAULINO (1996), guardam coerência com as estimativas feitas por GONÇALVES (1988), LANA et al. (1992b), PIRES et al. (1993a, b), FREITAS (1995), FONTES (1995) e ESTRADA (1997).

O aumento verificado no conteúdo de gordura corporal (total e em \% PCVZ), em animais de maior maturidade (tratamento 3), é coerente com as maiores proporções observadas de tecido adiposo na carcaça e maior espessura de gordura subcutânea

Tabela 3 - Média do conteúdo corporal total de proteína, gordura e energia por raça

Table 3 - Mean of total body content of protein, fat and energy per breed

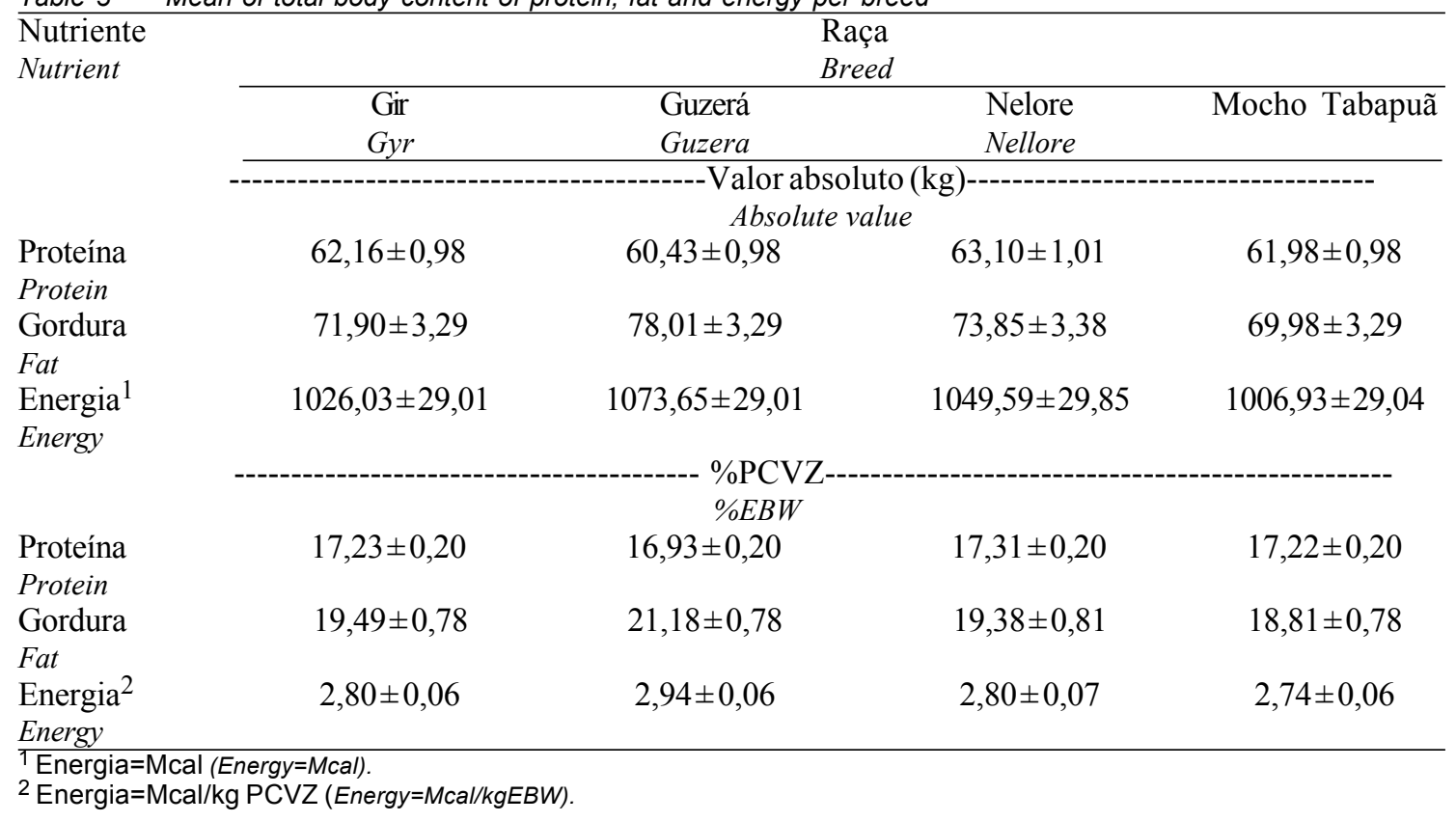


392 Rev. bras. zootec.

Tabela 4 - Média do conteúdo corporal total de macroelementos minerais por raça Table 4 - Mean of total body content of macrominerals per breed

\begin{tabular}{|c|c|c|c|c|}
\hline \multirow[t]{3}{*}{$\begin{array}{l}\text { Nutriente } \\
\text { Nutrient }\end{array}$} & \multicolumn{4}{|c|}{$\begin{array}{l}\text { Raça } \\
\text { Breed }\end{array}$} \\
\hline & Gir & Guzerá & Nelore & \multirow[t]{2}{*}{ Mocho Tabapuã } \\
\hline & $G y r$ & Guzera & Nellore & \\
\hline & \multicolumn{4}{|c|}{ 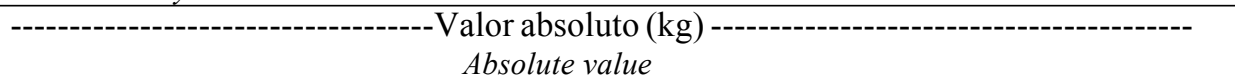 } \\
\hline $\mathrm{Ca}$ & $6,29 \pm 0,13$ & $6,12 \pm 0,13$ & $6,52 \pm 0,14$ & $6,37 \pm 0,13$ \\
\hline $\mathrm{P}$ & $2,92 \pm 0,06$ & $2,91 \pm 0,06$ & $3,11 \pm 0,06$ & $3,04 \pm 0,06$ \\
\hline $\mathrm{Mg}$ & $0,12 \pm 0,03$ & $0,11 \pm 0,03$ & $0,12 \pm 0,03$ & $0,12 \pm 0,03$ \\
\hline $\mathrm{Na}$ & $0,50 \pm 0,01$ & $0,46 \pm 0,01$ & $0,50 \pm 0,01$ & $0,50 \pm 0,01$ \\
\hline $\mathrm{K}$ & $0,75 \pm 0,02$ & $0,74 \pm 0,02$ & $0,72 \pm 0,02$ & $0,74 \pm 0,02$ \\
\hline \multirow[t]{2}{*}{$\mathrm{Ca}+\mathrm{P}+\mathrm{Mg}+\mathrm{Na}+\mathrm{K}$} & $10,58 \pm 0,20$ & $10,35 \pm 0,20$ & $10,99 \pm 0,20$ & $10,77 \pm 0,20$ \\
\hline & \multicolumn{3}{|c|}{$\% E B W$} & -- \\
\hline $\mathrm{Ca}$ & $1,77 \pm 0,04$ & $1,73 \pm 0,04$ & $1,79 \pm 0,04$ & $1,79 \pm 0,04$ \\
\hline $\mathrm{P}$ & $0,82 \pm 0,02$ & $0,82 \pm 0,02$ & $0,85 \pm 0,02$ & $0,85 \pm 0,02$ \\
\hline $\mathrm{Mg}$ & $0,03 \pm 0,001$ & $0,03 \pm 0,001$ & $0,03 \pm 0,001$ & $0,03 \pm 0,001$ \\
\hline $\mathrm{Na}$ & $0,14 \pm 0,002$ & $0,13 \pm 0,002$ & $0,14 \pm 0,02$ & $0,14 \pm 0,002$ \\
\hline $\mathrm{K}$ & $0,21 \pm 0,004$ & $0,21 \pm 0,004$ & $0,20 \pm 0,004$ & $0,20 \pm 0,004$ \\
\hline $\mathrm{Ca}+\mathrm{P}+\mathrm{Mg}+\mathrm{Na}+\mathrm{K}$ & $2,97 \pm 0,058$ & $2,91 \pm 0,058$ & $3,01 \pm 0,059$ & $3,02 \pm 0,058$ \\
\hline
\end{tabular}

Tabela 5 - Média do conteúdo corporal total de proteína, gordura e energia por tratamento ${ }^{3}$ Table 5 - Mean of total body content of protein, fat and energy per treatment ${ }^{3}$

\begin{tabular}{|c|c|c|c|c|c|}
\hline \multirow[t]{2}{*}{$\begin{array}{l}\text { Nutriente } \\
\text { Nutrient }\end{array}$} & \multicolumn{5}{|c|}{$\begin{array}{c}\text { Tratamento }^{3} \\
\text { Treatment }\end{array}$} \\
\hline & $\mathrm{AB}(I S)$ & $\operatorname{AR}(R F)$ & 1 & 2 & 3 \\
\hline \multicolumn{6}{|c|}{$\begin{array}{l}\text { - } \\
- \\
\text { Absolute value }\end{array}$} \\
\hline $\begin{array}{l}\text { Proteína } \\
\text { Protein }\end{array}$ & $51,54 \pm 1,0 \mathrm{~d}$ & $56,65 \pm 1,1 \mathrm{c}$ & $63,05 \pm 1,1 b$ & $66,80 \pm 1,1 b$ & $71,54 \pm 1,1 \mathrm{a}$ \\
\hline $\begin{array}{l}\text { Gordura } \\
\text { Fat }\end{array}$ & $40,85 \pm 3,4 \mathrm{~d}$ & $57,10 \pm 3,8 \mathrm{c}$ & $70,57 \pm 3,8 \mathrm{c}$ & $87,86 \pm 3,8 b$ & $110,81 \pm 3,8 \mathrm{a}$ \\
\hline $\begin{array}{l}\text { Energia } 1 \\
\text { Energy }\end{array}$ & $674,46 \pm 38,0 \mathrm{e}$ & $855,85 \pm 33,3 \mathrm{~d}$ & $1018,54 \pm 33,3 \mathrm{c}$ & $1202,04 \pm 33,4 b$ & $1444,37 \pm 33,3 \mathrm{a}$ \\
\hline \multicolumn{6}{|c|}{$\% E B W$} \\
\hline $\begin{array}{l}\text { Proteína } \\
\text { Protein } \\
\text { Gordura }\end{array}$ & $17,65 \pm 0,2 b$ & $17,79 \pm 0,2 \mathrm{a}$ & $17,39 \pm 0,2 \mathrm{c}$ & $16,84 \pm 0,2 \mathrm{c}$ & $16,19 \pm 0,2 \mathrm{~d}$ \\
\hline $\begin{array}{l}\text { Fat } \\
\text { Energia }^{2}\end{array}$ & $14,07 \pm 0,8 \mathrm{~d}$ & $17,87 \pm 0,9 \mathrm{c}$ & $19,51 \pm 0,9 \mathrm{c}$ & $22,11 \pm 0,9 b$ & $25,02 \pm 0,9 \mathrm{a}$ \\
\hline Energy & $2,32 \pm 0,1 \mathrm{e}$ & $2,68 \pm 0,1 \mathrm{~d}$ & $2,81 \pm 0,1 \mathrm{c}$ & $3,03 \pm 0,1 \mathrm{~b}$ & $3,26 \pm 0,1 \mathrm{a}$ \\
\hline $\begin{array}{c}\text { Médias, } r \\
{ }^{1} \text { Energia }= \\
1=405 \mathrm{k} \\
\text { Means, wit } \\
{ }^{1} \text { Energy }=M\end{array}$ & $\begin{array}{l}\text { a, seguidas de l } \\
\text { Energia=Mcal/k } \\
2=450 \mathrm{~kg} \mathrm{PV} ; 3 \\
\text { w, followed by dif } \\
\text { erav=Mcal/kg EBU }\end{array}$ & $\begin{array}{l}\text { S diferentes são d } \\
\mathrm{CVZ} ;{ }^{3} \mathrm{AB}=\text { abate } \\
00 \mathrm{~kg} \mathrm{PV} \text {. } \\
\text { t letters are differen } \\
\mathrm{s}=\text { initial slaughter (re }\end{array}$ & $\begin{array}{l}\text { ntes }(P<0,05) \text { pelo } \\
\text { ial (animais-referên } \\
\text { 05) by Tukey test. } \\
\text { cce-animals): } R F=\text { res }\end{array}$ & $\begin{array}{l}\text { te Tukey. } \\
\text {; AR = alimentaçãa }\end{array}$ & $\begin{array}{l}\overline{t r i t a} \text { (mantença); } \\
=405 \mathrm{~kg} L W ; 2=450\end{array}$ \\
\hline
\end{tabular}

(ESPGOR), em animais mais pesados.

Os animais do tratamento 3 apresentaram maiores $(\mathrm{P}<0,05)$ conteúdos corporais totais de macroelementos minerais que animais dos tratamentos $\mathrm{AB}, \mathrm{AR}$ e 1 , diferindo $(\mathrm{P}<0,05)$ somente do tratamento 2 quanto ao conteúdo de potássio. De maneira geral, observou-se que as quantidades totais de macroelementos minerais aumentaram com a elevação do peso corporal (maturidade). Por outro lado, os resultados mostraram tendência de decréscimo nas concentrações dos cinco macroelementos minerais no corpo vazio com a elevação do peso corporal 
Tabela 6 - Média do conteúdo corporal total de macroelementos minerais por tratamento

Table 6 - Mean of total body content of macrominerals per treatment

\begin{tabular}{|c|c|c|c|c|c|}
\hline \multirow[t]{2}{*}{$\begin{array}{l}\text { Nutriente } \\
\text { Nutrient }\end{array}$} & \multicolumn{5}{|c|}{$\begin{array}{c}\text { Tratamento }^{3} \\
\text { Treatment }\end{array}$} \\
\hline & $\mathrm{AB}(I S)$ & $\operatorname{AR}(R F)$ & 1 & 2 & 3 \\
\hline & \multicolumn{5}{|c|}{ 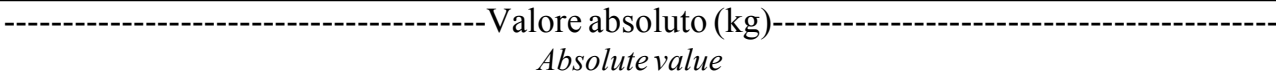 } \\
\hline $\mathrm{Ca}$ & $5,66 \pm 0,14 \mathrm{c}$ & $6,01 \pm 0,15 b c$ & $6,31 \pm 0,15 b$ & $6,72 \pm 0,16 a b$ & $6,94 \pm 0,15 a$ \\
\hline $\mathrm{P}$ & $2,64 \pm 0,06 \mathrm{~d}$ & $2,83 \pm 0,07 \mathrm{~cd}$ & $2,99 \pm 0,07 b c$ & $3,17 \pm 0,07 \mathrm{ab}$ & $3,35 \pm 0,07 a$ \\
\hline $\mathrm{Mg}$ & $0,01 \pm 0,003 c$ & $0,11 \pm 0,003 \mathrm{bc}$ & $0,12 \pm 0,003 b$ & $0,12 \pm 0,003 \mathrm{ab}$ & $0,13 \pm 0,003 a$ \\
\hline $\mathrm{Na}$ & $0,42 \pm 0,010 \mathrm{c}$ & $0,45 \pm 0,010 \mathrm{c}$ & $0,49 \pm 0,010 \mathrm{~b}$ & $0,53 \pm 0,010 \mathrm{a}$ & $0,56 \pm 0,010 \mathrm{a}$ \\
\hline K & $0,65 \pm 0,017 \mathrm{c}$ & $0,63 \pm 0,018 \mathrm{c}$ & $0,73 \pm 0,018 \mathrm{~b}$ & $0,78 \pm 0,018 b$ & $0,89 \pm 0,018 \mathrm{a}$ \\
\hline \multirow[t]{2}{*}{$\mathrm{Ca}+\mathrm{P}+\mathrm{Mg}+\mathrm{Na}+\mathrm{K}$} & $9,46 \pm 0,205 d$ & $10,04 \pm 0,23 \mathrm{~cd}$ & $10,64 \pm 0,23 b c$ & $11,33 \pm 0,23 \mathrm{ab}$ & $11,88 \pm 0,23 \mathrm{a}$ \\
\hline & & & $\% E B W$ & & \\
\hline $\mathrm{Ca}$ & $1,94 \pm 0,04 a$ & $1,89 \pm 0,05 \mathrm{ab}$ & $1,74 \pm 0,05 b c$ & $1,69 \pm 0,05 \mathrm{~cd}$ & $1,57 \pm 0,05 \mathrm{~d}$ \\
\hline $\mathrm{P}$ & $0,91 \pm 0,02 \mathrm{a}$ & $0,89 \pm 0,02 \mathrm{ab}$ & $0,82 \pm 0,02 b$ & $0,80 \pm 0,02 b c$ & $0,76 \pm 0,02 \mathrm{c}$ \\
\hline $\mathrm{Mg}$ & $0,03 \pm 0,001 \mathrm{a}$ & $0,03 \pm 0,001 \mathrm{ab}$ & $0,03 \pm 0,001 b$ & $0,03 \pm 0,001 b c$ & $0,03 \pm 0,001 \mathrm{c}$ \\
\hline $\mathrm{Na}$ & $0,14 \pm 0,002 \mathrm{a}$ & $0,14 \pm 0,003 \mathrm{a}$ & $0,13 \pm 0,003 b$ & $0,13 \pm 0,003 c$ & $0,13 \pm 0,003 \mathrm{c}$ \\
\hline K & $0,22 \pm 0,004 \mathrm{a}$ & $0,20 \pm 0,005 a$ & $0,20 \pm 0,005 b c$ & $0,20 \pm 0,005 c$ & $0,20 \pm 0,005 d$ \\
\hline $\mathrm{Ca}+\mathrm{P}+\mathrm{Mg}+\mathrm{Na}+\mathrm{K}$ & $3,25 \pm 0,060 \mathrm{a}$ & $3,16 \pm 0,066 \mathrm{ab}$ & $2,94 \pm 0,066 b c$ & $2,86 \pm 0,066 \mathrm{~cd}$ & $2,68 \pm 0,066 \mathrm{~d}$ \\
\hline \multicolumn{6}{|c|}{$\begin{array}{l}\text { Médias, na linha, seguidas de letras diferentes são diferentes }(\mathrm{P}<0,05) \text { pelo teste Tukey. } \\
1 \text { Energia=Mcal; } 2 \text { Energia=Mcal/kg PCVZ; } 3 \mathrm{AB}=\text { abate inicial (animais-referência); AR = alimentação restrita (mantença); } \\
1=405 \mathrm{~kg} \mathrm{PV;} 2=450 \mathrm{~kg} \mathrm{PV;} 3=500 \mathrm{~kg} \mathrm{PV} \text {. } \\
\text { Means, within a row, followed by different letters are different }(P<.05) \text { by Tukey test. }\end{array}$} \\
\hline \multicolumn{6}{|c|}{$\begin{array}{l}\text { Energy }=M c a l ;{ }^{2} \text { Energy=Mcal } / \mathrm{kg} \mathrm{EBW;}{ }^{3} / \mathrm{S}=\text { Initial slaughter (reference-animals); } R F=\text { restrict feeding (maintenance); } 1=405 \mathrm{~kg} L W ; 2= \\
450 \mathrm{~kg} \mathrm{LW} ; 3=500 \mathrm{~kg} \mathrm{LW} .\end{array}$} \\
\hline
\end{tabular}

vazio, o que, segundo PAULINO (1996), pode estar associado ao efeito de diluição provocado pelo aumento da gordura corporal, uma vez que a gordura tem baixo teor de minerais, e à constatação, no presente trabalho, de redução na proporção de ossos e aumento na de gordura da carcaça, em animais de maturidade mais elevada (categoria 3 ). O decréscimo na concentração de minerais verificado neste trabalho foi demonstrado por PAULINO (1996), encontrando suporte nos resultados de PIRES et al. (1993c, d), SOARES (1994), FONTES (1995) e ESTRADA (1997).

\section{Conclusões}

As raças não diferiram quanto ao conteúdo corporal de gordura, proteína, energia e macroelementos minerais.

Animais abatidos com pesos mais elevados apresentaram menores porcentagens de proteína e de macroelementos minerais ( $\mathrm{Ca}, \mathrm{P}, \mathrm{Mg}, \mathrm{Ke} \mathrm{Na}$ ) no corpo, o inverso ocorrendo em relação à gordura, quando comparados a animais abatidos com pesos mais leves.

\section{Referências Bibliográficas}

AGRICULTURAL RESEARCH COUNCIL - ARC. 1980. The nutrient requirements of ruminants livestock. London:
Commonwealth Agricultural Bureaux, 351p.

BRAGA, J. M., DEFILIPO, B. V. 1979. Determinação espectrofotométrica de fósforo em extrato de solos e matéria vegetal. $R$. Ceres, 21(113):73-75.

CARVALHO, D. R. Composição corporal e exigências nutricionais de macroelementos inorgânicos de bovinos. Viçosa, MG: UFV, 1989. 84 p. Dissertação (Mestrado em Zootecnia) - Universidade Federal de Viçosa, 1989.

ESTRADA, L.H.C., FONTES, C. A. A., JORGE, A.M. et al. 1997. Exigências nutricionais de bovinos não-castrados em confinamento. 1.Conteúdo corporal e exigências líquidas de proteína e energia para ganho de peso. R. Bras. Zootec., 26(3):575-583.

FONTES, C. A. A. Composição corporal, exigências líquidas de nutrientes para ganho de peso e desempenho produtivo de animais zebuínos e mestiços europeu-zebu. Resultados experimentais. In: PEREIRA, J. C. (Ed). SIMPÓSIO INTERNACIONAL SOBRE EXIGÊNCIAS NUTRICIONAIS DE RUMINANTES, 1995, Viçosa, MG. Anais...Viçosa, MG: CARD, p. 419-455, 1995.

FREITAS, J. A. Composição corporal e exigência de energia e proteína de bovinos (zebuínos e mestiços) e bubalinos não castrados, em confinamento. Viçosa, MG: UFV, 1995. 132p. Dissertação (Mestrado em Zootecnia) - Universidade Federal de Viçosa, 1995.

GONÇALVES, L.C. Digestibilidade, composição corporal, exigências nutricionais e características das carcaças de zebuínos, taurinos e bubalinos. Viçosa, MG: UFV, 1988. 238p. Tese (Doutorado em Zootecnia) - Universidade Federal de Viçosa, 1988.

HANKINS, O.G., HOWE, P.E. Estimation of the composition of beef carcasses and cuts. Washington, D. C., 1946 (Tech. Bulletin - USDA, 926).

HARVEY, W. R. 1987. Mixed model least squares and maximum 
394 Rev. bras. zootec.

likelihood computer program (LSMLMW) Versão PC - 1 .

LANA, R. P., FONTES, C. A. A., PERON, A. J. et al. 1992b. Composição corporal e do ganho de peso e exigências de energia, proteína e macroelementos minerais $(\mathrm{Ca}, \mathrm{P}, \mathrm{Mg}, \mathrm{Na}$ e K) de novilhos de cinco grupos raciais. 1. Conteúdo corporal e do ganho de peso em gordura, proteína e energia. $R$. Soc. Bras. Zootec., 21(3):518-527.

LANA, R. P., FONTES, C. A. A., PERON, A. J. et al. 1992c. Composição corporal e do ganho de peso e exigências de energia, proteína e macroelementos minerais ( $\mathrm{Ca}, \mathrm{P}, \mathrm{Mg}, \mathrm{Na}$ e K) de novilhos de cinco grupos raciais. 2. Exigências de energia e proteína. R. Soc. Bras. Zootec., 21(3):528-537.

LANA, R. P., FONTES, C. A. A., PERON, A. J. et al. 1992d. Composição corporal e do ganho de peso e exigências de energia, proteína e macroelementos minerais $(\mathrm{Ca}, \mathrm{P}, \mathrm{Mg}, \mathrm{Na}$ e K) de novilhos de cinco grupos raciais. 3. Conteúdo corporal e do ganho de peso e exigências de macroelementos minerais. R. Soc. Bras. Zootec. 21(3):538-544.

LANA, R. P., FONTES, C. A. A., PERON, A. J. et al. 1992a. Conteúdo do trato gastrintestinal (digesta) e sua relação com o peso, em novilhos de cinco grupos raciais e bovinos machos inteiros. R. Soc. Bras. Zootec., 21(3):510-517.

NATIONAL RESEARCH COUNCIL - NRC. 1984. Nutrient requeriments of beef cattle. 6. ed. Washington, D. C., 90p.

PAULINO, M. F. Composição corporal e exigências de energia, proteína e macroelementos minerais (Ca, $\mathrm{P}, \mathrm{Mg}, \mathrm{Na}$ e K) de bovinos não-castrados de quatro raças zebuinas em confinamento. Viçosa, MG: UFV, 1996. 80p. Tese (Doutorado em Zootecnia) - Universidade Federal de Viçosa, 1996.

PIRES, C. C., FONTES, C. A. A., GALVÃO, J. G. et al. 1993a. Exigências nutricionais de bovinos de corte em acabamento. I. Composição corporal e exigências de proteína para ganho de peso. R. Soc. Bras. Zootec., 22(1):110-120.

PIRES, C. C., FONTES, C. A. A., GALVÃO, J. G. et al. 1993 b. Exigências nutricionais de bovinos de corte em acabamento. II. Exigências de energia para mantença e ganho de peso. $R$. Soc. Bras. Zootec., 22(1):121-132.
PIRES, C. C., FONTES, C. A. A., GALVÃO, J. G. et al. 1993c. Exigências nutricionais de bovinos de corte em acabamento. III. Exigências de cálcio e fósforo para ganho de peso. R. Soc. Bras. Zootec., 22(1):133-143.

PIRES, C. C., FONTES, C. A. A., GALVÃO, J. G. et al. 1993d. Exigências nutricionais de bovinos de corte em acabamento. IV. Exigências de magnésio, sódio, potássio. R. Soc. Bras. Zootec., 22(1):144-154.

SILVA, D. J. 1990. Análise de alimentos (métodos químicos e biológicos). Viçosa, MG: UFV, 165p.

SOARES, J. E. Composição corporal e exigências de macroelementos minerais ( $\mathrm{Ca}, \mathrm{P}, \mathrm{Mg}$, Na e K) para ganho de peso em bovinos (zebuínos e taurinos) e bubalinos. Viçosa, MG: UFV, 1994. 77p. Dissertação (Mestrado em Zootecnia) - Universidade Federal de Viçosa, 1994.
Recebido em: 03/06/98

Aceito em: 22/09/98 